\title{
Educar para um futuro mais sustentável e inclusivo
}

\section{CLAUDIA COSTIN ${ }^{I}$}

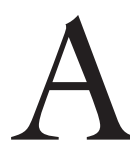

PANDEMIA trouxe-nos sofrimentos próprios de uma crise multifacetada. Afinal, trata-se tanto de uma crise sanitária, com perdas de vidas e adoecimento, quanto uma crise econômica, o que resultou em desemprego e redução substancial de renda, institucional, com o fortalecimento de opções políticas populistas representando riscos à democracia e educacional, com cerca de 190 países tendo fechado total ou parcialmente suas escolas.

Em educação, a Covid-19 não apenas resultou em perdas de aprendizagem, especialmente para os alunos que vêm de famílias mais vulneráveis, como desvelou a profunda desigualdade educacional que vivemos, particularmente no Brasil.

Nesse contexto, somos levados a refletir não só sobre as emergências impostas pela situação, como sobre o que se pretende construir para um futuro pós-pandemia. O que estava encoberto aparece e nos convoca e enfrentar atuais e novos desafios educacionais do país, com uma clara percepção de que é educação de qualidade que constrói um processo de desenvolvimento mais inclusivo e sustentável. E é sobre isso que escrevo este texto para a edição de número 100 da revista Estudos Avançados.

Em setembro de 2015, na Assembleia Geral da ONU, foram aprovados os Objetivos do Desenvolvimento Sustentável (ODS). Vinham substituir e ampliar os antigos objetivos do milênio, em que se pensava em preparar os países para o século XXI. Mais ambiciosos que os anteriores, os ODS tinham que lidar com novas questões que assolavam o planeta: apesar de avanços em alguns indicadores sociais e de redução de danos ao futuro do planeta, a lentidão das políticas públicas e a falta de ousadia na construção de soluções por parte dos decisores foram agravadas com o advento do que se passou a denominar de $4^{\text {a }}$ Revolução Industrial.

Esse novo processo se traduz numa aceleração da automação e da robotização, com a Inteligência Artificial substituindo trabalho humano por algoritmos, o que pode ser uma bênção e uma maldição, dependendo das respostas regulatórias e das políticas públicas adotadas. Uma bênção, pois se bem coordenado, o processo pode eliminar trabalho em condições indignas e pouco saudáveis, como ocorreu, em alguns casos, com a mecanização precedente. Pode também trazer consigo uma redução da destruição de recursos naturais ao possibilitar processos de trabalho menos geradores de desperdícios ou de emissões. 
Mas, apesar de se saber que, em etapas anteriores de mecanização, a criação de postos de trabalho a partir de inovações tecnológicas superou a destruição, há hoje um certo ceticismo em relação a essa possibilidade. Haverá trabalho para todos, e, em caso positivo, não teremos um grande aumento da desigualdade social? Não sabemos ainda ao certo, mas tudo indica que, se a criação líquida de postos de trabalho for positiva, eles não demandarão as mesmas competências e isso poderá resultar em importantes instabilidades e incertezas.

Ora, a mistura tóxica de desemprego com aumento de desigualdade social, ambos agravados pela Covid-19, não promete coesão social nem um futuro sustentável no sentido mais amplo do termo.

Da mesma maneira, os avanços em biotecnologia, que podem ter importante papel na prevenção e cura de doenças e assim possibilitar uma extensão da vida com qualidade, também podem representar um risco, se perdermos a visão de equilíbrio dos ecossistemas e daquilo que nos faz humanos. Há mesmo sentido em prolongar os anos nos transformando em autômatos, com perda eventual da capacidade de sentirmos raiva, tristeza, frustração ou até paixão?

Mas vou me ater, neste texto, a duas questões relevantes para os próximos 25 anos: como dotar as novas gerações das competências necessárias para a vida em sociedade, em especial para o trabalho e a cidadania global; e como neles instilar, por meio da educação, valores que contribuam para assegurar que sua existência não coloque em risco a dos atuais e futuros habitantes do planeta.

\section{Educação e os objetivos do desenvolvimento sustentável}

O Objetivo de Desenvolvimento Sustentável 4 estabelece que, até 2030 (portanto, a menos de dez anos de quando escrevo o artigo), iremos assegurar educação inclusiva, equitativa e de qualidade, e promover oportunidades de aprendizado ao longo da vida para todos.

Há nesse enunciado uma busca de equilibrar duas questões muito caras à educação: excelência e equidade. Em outros termos, há uma promessa de que a qualidade que se quer construir não será obtida, como é costumeiro ocorrer, por meio de exclusões.

As metas em que se desdobra esse objetivo deixam isso ainda mais claro: a ideia, por exemplo, de se garantir que todos concluam - e não apenas frequentem - a escola primária e secundária (no nosso caso, o Ensino Médio, o que não ocorre hoje) já é, em si mesma, ousada. Mas, completa o enunciado da meta 4.1, "livre, equitativa e de qualidade e que se traduza em resultados de aprendizagem relevantes e efetivos". Ou seja, além de completar os estudos secundários, a educação oferecida a crianças e jovens não deve resultar em aprendizados importantes apenas para alguns e não para outros.

Entre as metas, inclui-se também uma muito importante para a equidade, a 4.2, que estabelece que, até 2030, programas de Primeira Infância de qualidade serão oferecidos para todos, inclusive educação pré-escolar, de forma a preparar meninas e meninos para as etapas posteriores de escolaridade. 
Outras metas dizem respeito à igualdade de acesso a todos os níveis de escolaridade entre homens e mulheres, pessoas de diferentes grupos étnicos, permitindo também que isso ocorra para jovens oriundos de meios vulneráveis ou portadores de deficiências. Em muitos casos, para isso, ações afirmativas podem ser necessárias, dando apoio adicional a escolas ou alunos que dele necessitem. O ODS também inclui uma meta para assegurar que aumente de forma expressiva o número de jovens e adultos com habilidades relevantes - inclusive competências técnicas - para empregabilidade e empreendedorismo, o que será vital no contexto da $4^{\text {a }}$ Revolução Industrial, com a extinção progressiva de inúmeros postos de trabalho.

Mas não basta garantir direitos e um acesso qualificado ao mundo do trabalho. A educação tem um papel ainda maior na construção de uma sociedade que respeite a vida, promova a paz e permita uma existência de qualidade para as novas gerações no planeta.

Assim, a meta 4.7 estabelece que, até 2030, vamos garantir "que todos os alunos adquiram conhecimentos e habilidades necessárias para promover o desenvolvimento sustentável", aprendendo a desenvolver estilos de vida sustentáveis, a promover direitos humanos, igualdade de gênero, "uma cultura de paz e não violência, cidadania global e valorização da diversidade cultural".

Sim, é fundamental desenvolver as competências básicas nos jovens, como letramento, raciocínio matemático e científico e oferecer-lhes um repertório cultural relevante. Mas é bom lembrar que, no século XX, pessoas que receberam educação formal de qualidade para o padrão da época, inclusive Ensino Superior, foram capazes de perpetrar atrocidades em nome do orgulho nacional e de uma distopia excludente. Formar cidadãos globais capazes de enxergar a humanidade no outro, num processo empático, e não destruir os recursos do planeta num "consumerismo" desenfreado e apoiado em teorias anticientíficas é, neste século, um papel fundamental da escola.

\section{Tendências da educação no século XXI e a sustentabilidade}

Quando pensamos a educação para os próximos 25 anos, temos que considerar duas possibilidades de análise: a) como será e como deveria ser a educação daqui a 25 anos, e b) como preparar os alunos para a realidade que viverão daqui a 25 anos.

Creio que sejam abordagens complementares e o campo normativo implícito na primeira possibilidade de análise contém as respostas para a segunda. Afinal, a educação do futuro depende do que faremos nas escolas de hoje, especialmente se nosso foco de atenção é a sustentabilidade.

Há um arsenal de estudos prospectivos que tentam definir tendências em educação, mas não para um período tão longo. É difícil antecipar, por exemplo, se avanços na bioengenharia levarão à transferência de saberes por meio de chips ou manipulação genética. Evidentemente, isso traria consequências funestas para a riqueza que é a aprendizagem, como um processo construído socialmente. 
Nesse sentido, vou tentar me basear em projeções que se limitam a 2030 e procurar extrapolar tendências para os anos seguintes.

No documento Trends Shaping Education 2019, da OCDE (2019) algumas tendências que ocorrem hoje no mundo são identificadas como forças que tenderão a moldar a educação do futuro. É importante entendê-las para projetar a possível configuração futura da área.

Entre elas se destacam:

- Aumento da mobilidade, com a redução de tempo e recursos gastos em deslocamentos, o que favorece a criação de um mercado global, mas, ao mesmo tempo, associa-se a uma intensificação das migrações, acarretando dificuldades logísticas e culturais para a educação de populações deslocadas;

- Automação, digitalização e o advento da Inteligência Artificial com a consequente extinção acelerada de postos de trabalho, com riscos de aumento da desigualdade social e do desemprego;

- Deslocamento do eixo econômico com a emergência de economias gigantes, especialmente a Índia e a China

- Envelhecimento das sociedades e a consequente redução de população educacional, especialmente nos países desenvolvidos e em parte dos em desenvolvimento.

Frente a essas tendências, a educação precisará se transformar de forma importante. Mas é preciso lembrar que a Covid-19, além de desvelar as piores facetas da nossa educação, também funcionou como uma aceleradora de futuros. Nesse sentido, algumas das tendências acima apontadas foram aceleradas, como a digitalização e automação, que pode ser simultaneamente uma maldição e uma benção, como afirmei mais no ineicio do texto. Maldição por substituir trabalho humano em vários setores por máquinas, e uma bênção por nos permitir, a partir de aprendizagens ocorridas no isolamento social vivido na pandemia, apoiar a ação de professores no processo de ensino-aprendizagem. Mesmo com a reduzida experiência que os docentes tinham no uso de ferramentas digitais no processo de ensino-aprendizagem, a pandemia obrigou vários deles a aprender na prática, de forma a assegurar alguma forma de interação pedagógica com seus alunos.

Essa aprendizagem poderá, no futuro, ser a base para construção de um Ensino Híbrido em que, num conceito de sala de aula invertida, professores remetam as exposições para serem assistidas em casa, focando o seu trabalho no que hoje se faz, muitas vezes, como deveres de casa, ou seja a aplicação dos conteúdos aprendidos em problemas da realidade. Dessa forma, os mestres passarão a atuar muito menos como meros fornecedores de aulas expositivas e muito mais como asseguradores de aprendizagem mais aprofundada, que ensine os alunos a pensar.

Além disso, se considerarmos esse cenário de automação e robotização aceleradas, é importante notar que, apesar de novos postos de trabalho pode- 
rem ser criados, eles não demandarão as mesmas competências de hoje. Isso quer dizer que teremos que enfatizar, nas escolas, o desenvolvimento de habilidades que nos diferenciam de máquinas e nos tornam essencialmente humanos.

Precisaremos também construir uma educação que nos possibilite avançar para além do mero cumprimento dos ditames do ODS 4, em especial para garantir autonomia, empregabilidade ou empreendedorismo e cidadania global e enfrentar alguns riscos associados a um eventual crescimento de desigualdades sociais, como o fortalecimento de governos populistas e autoritários.

As principais características da educação no futuro, nesse sentido, são:

- Foco em resolução colaborativa e criativa de problemas, habilidade que já chamou a atenção do Pisa, levando a OCDE a inclusive criar uma prova específica a respeito;

- Personalização do ensino, que possibilitará uma aprendizagem mais customizada para cada educando, considerando suas deficiências e seu potencial, por meio de plataformas adaptativas apoiadas por Inteligência Artificial;

- Flexibilização dos currículos e interdisciplinaridade - para combater a fragmentação das áreas de conhecimento em disciplinas que tem levado à superficialidade nas abordagens e dificultado maior aprofundamento;

- Desenvolvimento de competências do século XXI como as socioemocionais, a experimentação e a autonomia e protagonismo do estudante, associando-as a competências cognitivas;

- Fortalecimento do ensino de pensamento crítico e sistêmico. De acordo com Joseph Aoun (2017), no seu magnífico Robot-Proof. Higher Education, isto é fundamental inclusive no Ensino Superior, já que, no futuro, a Inteligência Artificial não apenas substituirá trabalho humano, mas vai demandar pensamento abstrato em mais alto nível;

- Desenvolvimento nos estudantes de uma agilidade cultural, que lhes permita navegar bem nos contextos mais diversos, entendendo os pressupostos e valores próprios de cada povo, sem cair em relativismos e preservando conquistas humanitárias;

- Criação de um ecossistema educacional que inclua Universidades, escolas, plataformas digitais, instituições de formação técnica e agências de aconselhamento de competências para adultos frente às eventuais ondas de extinção de postos de trabalho;

- Formação de crianças e adolescentes para a cidadania global, promovendo a empatia, formas de comunicação e interação social não agressivas e combatendo visões xenófobas, racistas e excludentes;

- Promoção do sentido de responsabilidade, em crianças, jovens e adultos, pelos destinos do planeta e pela adoção de hábitos de vida e consumo mais sustentáveis. 


\section{A educação no Brasil e a sustentabilidade}

O Brasil demorou muito para ampliar o acesso à educação, e ainda tem desafios nesse sentido. Em 1930, tínhamos apenas $21,5 \%$ das crianças no Fundamental 1, antigo curso primário, enquanto a Argentina contava com 61,3\% e o Chile, $55,6 \%$ (Lindert, 2004, p.92-3). No final da década de 1960, ainda não passávamos de $40 \%$ das crianças frequentando as escolas, e apenas universalizamos o acesso no final dos anos 1990. Alguns anos depois foi a vez do Ensino Fundamental 2.

Hoje ainda temos cerca de 1,3 milhão de jovens de 15 a 17 anos, idade correta para o Ensino Médio, fora da escola, e a taxa de escolarização nessa etapa é de $87,2 \%$, embora muitos apresentem atraso escolar. Na última etapa da educação básica, apenas $59 \%$ dos alunos terminam, até os 19 anos, portanto dois anos depois da idade correta.

Mas nossos problemas não se limitam a acesso e a atraso escolar. Vivemos o que o Banco Mundial denominou de crise de aprendizagem em seu "World Development Report" de 2018 (World Bank, 2018). Sim, as crianças e jovens estão, em números crescentes, na escola, mas não estão aprendendo.

Os resultados do Pisa de 2018, avaliação internacional de qualidade da educação organizada pela OCDE e aplicada em jovens de 15 anos, colocam o Brasil numa situação difícil em termos de aprendizagem. Dos estudantes brasileiros que participaram nessa edição do exame, demonstraram não possuir o nível básico 68,1\% em matemática, 50\% em leitura e 55\% em ciências. Países de renda muito mais baixa que a nossa tiveram melhores resultados.

Mesmo segregando os resultados por nível socioeconômico dos alunos, o desempenho dos mais ricos da amostra brasileira não se compara bem com o do mesmo quartil de renda de muitos países. Há algo de profundamente errado no nosso sistema educacional.

A atratividade da carreira de professor e a formação que eles recebem no Ensino Superior é certamente uma das causas mais importantes desse cenário desafiador. É fundamental melhorar os salários, profissionalizar a carreira e a preparação para o seu desempenho. Em outros termos, para que todos aprendam, com equidade e níveis altos de expectativas para cada aluno, é preciso acabar de construir a escola do século XX, e isso precisa ser feito urgentemente.

Mas isso não será suficiente num mundo em rápida transformação, em que competências novas passam a ser exigidas para se ter acesso a trabalho e renda dignos e não se ver substituído por robôs. Assim, teremos que edificar simultaneamente a escola do século XX e a do século XXI.

Para tanto, ante os riscos do século, já visíveis no Brasil, como aumento da desigualdade, automação e robotização aceleradas, extinção de postos de trabalho, pandemias, emergência de populismos e danos ao ambiente resultantes de hábitos de consumo e processos produtivos inadequados, temos que transformar a educação brasileira com um sentido de urgência. Algumas propostas, nessa direção, mesmo que insuficientes, já estão sendo implementadas, tais como: 
- Implementação da recentemente aprovada Base Nacional Comum Curricular (BNCC), que estipula as aprendizagens necessárias para todos os brasileiros, a cada nível de escolaridade, numa visão bastante contemporânea. A BNCC está sendo traduzida agora em currículos subnacionais e escolares, o que já foi feito para a Educação Infantil e o Ensino Fundamental - e incluirá formação de professores para sua utilização e elaboração de materiais curriculares. Essas aprendizagens incluem uma Educação transversal para a cidadania e a sustentabilidade;

- Elaboração de uma Base Nacional Docente, recentemente aprovada pelo Conselho Nacional de Educação e homologada pelo MEC, que quebra o distanciamento atualmente existente entre teoria e prática na formação inicial dos professores, abrindo o caminho para uma atuação mais propensa ao ensino do pensamento sistêmico e crítico, tão relevante para o ensino de competências do século XXI e de uma educação para a sustentabilidade e a cidadania global;

- Avaliações de larga escala que permitem identificar os avanços e desafios das redes de ensino no desenvolvimento de algumas competências básicas e que preparam as escolas para realizarem suas próprias avaliações. Com isso, professores e gestores educacionais começam a aprender a trabalhar com dados mais precisos sobre a aprendizagem de cada aluno e a planejar melhor seu processo de ensino;

- Avanços na direção de um ensino híbrido, com a possibilidade de se combinar aulas presenciais com um professor preparado em metodologias ativas e o uso de formas não presenciais de aprendizagem, especialmente por meio digital, a ser assegurada por maior conectividade nas escolas e nas residências, com boa curadoria de conteúdos e autoria de professores, permitindo, no futuro, a implementação do conceito de sala de aula invertida, deixando as aulas expositivas para serem assistidas em casa, enquanto o professor atua na escola aplicando os conceitos aprendidos em problemas concretos da realidade.

Mas ainda falta muito para recuperarmos os buracos que deveríamos ter sanado em educação no século passado e mais ainda para nos prepararmos para os próximos 25 anos. Precisaremos, entre outras medidas:

- Criar uma cultura escolar que combine excelência com equidade, de forma convergente com o ODS 4 - com altas expectativas para todos;

- Tornar a profissão de professor atrativa, com bons salários, contratos não fragmentados e maior reconhecimento social da profissão;

- Usar a tecnologia, inclusive a Inteligência Artificial, para apoiar a ação de professor na personalização do processo de ensino;

- Ampliar a jornada escolar, incluindo tempo para um processo de aprendizagem mais aprofundado e menos fragmentado, assim como para garantir um espaço para o protagonismo juvenil e discussão dos sonhos e projetos de vida de cada aluno; 
- Criar agências de aconselhamento de competências tanto para jovens que estejam em escolas ou universidades quanto para trabalhadores em transição de postos de trabalho;

- Incentivar o ensino híbrido, com uso de plataformas de educação a distância, permitindo autonomia do educando e aprendizagem ao longo da vida, inclusive aquela que possibilite, como sugerido no relatório da Comissão Global sobre o Futuro do Trabalho da OIT (ILO, 2019) “a lifelong active society” ou, em tradução livre, uma sociedade ativa ao longo da vida;

- Investir em bioengenharia para apoiar a educação de crianças, jovens e adultos com deficiência e melhorar sua qualidade de vida;

- Envolver os educandos, crianças, jovens e adultos, em projetos transformacionais de recuperação do ambiente e de proteção do planeta contra danos futuros.

Essa relação não é exaustiva e sequer procura fazer um exercício preciso de futurologia. Baseia-se no que já vemos começando a ocorrer, com apoio de tecnologias emergentes.

\section{À guisa de conclusão}

A velocidade das transformações que vivemos não nos permite antecipar em detalhes o que deve ocorrer com a humanidade nos próximos 25 anos, menos ainda em uma área complexa como a educação. Procurei aqui apenas apontar alguns desafios que podem ser enfrentados nesse espaço de tempo, para nos colocar numa direção melhor frente a algumas tendências atuais e alguns riscos que o futuro nos apresenta.

Por razões de espaço, concentrei-me na educação básica, ou seja, a que vai da educação infantil até o fim do Ensino Médio. Mesmo assim, apontei aqui apenas algumas transformações que devem ocorrer nos próximos anos.

Em outros textos, valeria a pena analisar as mudanças que devem ocorrer no Ensino Técnico e Profissional e no Ensino Superior.

Procurei também, propositadamente, evitar citações e notas de pé de página, para não tornar o texto enfadonho.

O futuro depende do que faremos agora, e no caso da educação, em que se formam novas gerações com o saber acumulado de quem veio antes, mas também para que sejam disruptivos e construam um novo caminho, há que haver um sentido de urgência. O futuro é agora!

\section{Referências}

AOUN, J. E. Robot-Proof: Higher Education in the age of Artificial Intelligence. Cambridge, Massachusetts: The MIT Press, 2017.

INTERNATIONAL LABOUR ORGANIZATION - Global Commission on the Future of Work-2019. Work for a Brighter Future. Genève: International Labour Office, 2019. 
LINDERT, P. Growing Public: social spending and economic growth since the eighteenth century. Cambridge: Cambridge University Press, 2004.

OECD. Trends shaping education 2019. Paris: OECD Publishing, 2019.

WORLD BANK. World Development Report 2018: Learning to realize education's promise. World Bank Publications, 2018.

RESUMO - O artigo procura se debruçar sobre as atuais tendências em educação básica no Brasil, frente ao que vem ocorrendo na pandemia, aos compromissos que o Brasil assumiu em 2015, com relação à sustentabilidade e, em particular, o Objetivo do Desenvolvimento Sustentável 4 e à chamada Revolução 4.0, que tende a eliminar de forma acelerada postos de trabalho. Procura mostrar que habilidades deverão ser desenvolvidas nos estudantes para assegurar no futuro acesso a um mundo do trabalho que poderá ser marcado por exclusões e crescente desigualdade social. Destaca também a necessária formação para uma relação mais saudável com o planeta e para o exercício de uma cidadania global compatível com o século XXI.

PALAVRAS-CHAVE: Educação, Sustentabilidade, Futuro, Trabalho, Cidadania.

ABSTRACT - The article aims to tackle the present trends in K-12 education in Brazil with regard to what is happening with Covid 19, to the pursuit of sustainability and, in particular, to the Sustainable Development Goal-SDG 4 and the so-called "Revolution 4.0", set to rapidly extinguish job posts. The essay attempst to show the abilities that will have to be developed by students to ensure, in the future, access to a labor market that might be framed by exclusions and growing social inequality. It also highlights the requisite education for a healthier relationship with the planet and for a global citizenship compatible with the $21^{\text {st }}$ century.

KEYWORDS: Education, Sustainability, Future, Work, Citizenship.

Claudia Costin é diretora do Centro de Excelência e Inovação em Políticas Educacionais (Ceipe) da Fundação Getulio Vargas, Rio de Janeiro. É membro do Conselho Deliberativo do Instituto de Estudos Avançados da USP. @ - claudiacostin@hotmail.com / https://orcid.org/0000-0001-9456-5413.

Recebido em 6.10.2020 e aceito em 9.10.2020.

${ }^{\mathrm{I}}$ Centro de Excelência e Inovação em Políticas Educacionais, Fundação Getulio Vargas, Rio de Janeiro, Brasil. 
